\title{
PostScript
}

LETTERS

\section{Lung function decline in laboratory animal workers}

In their recent paper Portengen and colleagues $^{1}$ have made an important contribution to our understanding of laboratory animal allergy. However, they have omitted to draw attention to an observation of clinical importance to occupational physicians.

They have suggested that the lack of decline in lung function in "experienced" workers may be due to the healthy worker effect. Their suggestion is not supported by their own data: the decline in lung function over two years among newly exposed workers with symptoms of LAA was not significant and surprisingly there was a significant increase in function among the symptomatic experienced workers. This being the case there seems little reason to conclude that the loss of symptomatic workers (due to a healthy worker effect) would adequately explain the absence of a decline in function. An equally valid conclusion is that the effect observed in newly exposed workers is small and may not be sustained in the long term.

Physicians are wise not to preclude sensitised workers and those with symptoms of LAA from work with animals solely on the basis of concern that this may have a deleterious effect on health. ${ }^{2-4}$ Portengen et al have provided new evidence that supports this.

I agree that the results and conclusions should be interpreted with caution and that further work is needed. However, this is a reassuring study, with important implications for current animal workers and their health providers.

R M Preece

UK Occupational Health, AstraZeneca, Mereside Alderley Park, Macclesfield SK10 4TF, UK richard.preece@astrazeneca.com doi: 10.1136/oem.2003.011767

\section{References}

1 Portengen L, Hollander A, Doekes G, et al. lung function decline in laboratory animal workers: the role of sensitisation and exposure. Occup Environ Med 2003:60:870-5

2 Botham PA, Lamb CT, Teasdale EL, et al. Allergy to laboratory animals: a follow-up study of its incidence and of the influence of atopy and preexisting sensitization on its development. Occup Environ Med 1995;52:129-33.

3 Newill CA, Evans R III, Khoury M. Preemployment screening for allergy to laboratory animals: epidemiologic evaluation of its potential usefulness J Occup Med 1986:28: 1158-64.

4 Preece R, Renstrom A. Laboratory animal allergy. In: Hau van Hoosier GL, ed. Handbook of laboratory animal science, essential principles and practices, Vol. I, 2nd edn. Boca Raton, FL: CRC Press, 2002.

\section{Authors' reply}

We would like to thank Dr Preece for his letter. He raises the issue that loss of symptomatic workers during follow up does not explain the absence of a decline in lung function in workers who worked with laboratory animals for more than four years, and concludes that lung function decline in short term employed workers is not sustained. We think that this interpretation of our data is somewhat overoptimistic and is based on the assumption that lung function changes are similar in those lost to follow up and those available for follow up, and that short term and long term employed workers can be compared. In our paper we analysed lung function decline separately for long term and short term employed workers as there were strong indications that those working with laboratory animals for more than four years were less likely to experience adverse health effects due to contact with laboratory animals. Workers lost to follow up were more often sensitised to laboratory animals and more often reported allergic and chronic respiratory symptoms. In addition, long term employed workers were less likely to become sensitised to laboratory animals during follow up (unpublished data). Long term effects in the recently employed workers should therefore not be inferred from (the lack of) effects in this survivor population.

We also do not agree that an excess decline in $\mathrm{FEV}_{1}$ in the order of $80 \mathrm{ml} / \mathrm{y}$ for exposed and sensitised short term employed workers can be qualified as a "small" effect. From a public health point of view such a decline implies more than a tripling of the normal decline due to aging, and is larger than the excess decline found in populations of heavy smokers. ${ }^{1-3}$ The estimated decline in $\mathrm{FEV}_{1}$ for symptomatic short term employed workers was $-22 \mathrm{ml} / \mathrm{y}$, which is similar in magnitude to the norma decline due to aging. Although this estimate was not statistically significant, we think this is mainly an issue of statistical power.

The fact that we found no additional lung function decline due to allergen exposure in sensitised long term employed workers may also be related to qualitative or quantitative aspects of exposure. The exposure measure we used to characterise exposure during follow up was rather crude and might have failed to capture relevant differences in exposure level among the long term employed workers. On a final note, we would like to point out that the models we used are best suited to identify aetiological factors and should not be used for predictive purposes An article on diagnostic modelling, explicitly dealing with laboratory animal allergy has been published in this journal quite recently. and is recommended reading for the interested occupational physician.

L Portengen, A Hollander, G Doekes, G de Meer, D Heederik

Institute for Risk Assessment Sciences (IRAS), Utrech University, PO Box 80176, 3508 TD, Utrecht Netherlands; L.Portengen@iras.uu.n

\section{References}

1 Xu X, Dockery DW, Ware JH, et al. Effects of cigarette smoking on rate of loss of pulmonary function in adults: a longitudinal assessment. Am Rev Respir Dis 1992;146:1345-8.

2 Burchfiel CM, Marcus EB, Curb JD, et al. Effects of smoking and smoking cessation on longitudinal decline in pulmonary function. Am J Respir Crit Care Med 1995; 151:1778-85.

3 Anthonisen NR, Connett JE, Murray RP. Smoking and lung function of Lung Health Study participants after 11 years. Am J Respir Crit Care Med 2002; 166:675-9.

4 Meijer E, Grobbee DE, Heederik D. Detection of workers sensitised to high molecular weight allergens: a diagnostic study in laboratory animal workers. Occup Environ Med 2002;59:189-95.

\section{Asthma and swimming pools: statistical issues}

Bernard and colleagues ${ }^{1}$ presented results from several studies investigating childhood asthma in relation to swimming pool use. Though the studies were generally well conducted, there are some respects in which the statistical analysis and interpretation are misleading.

The study of asthma prevalence in relation to swimming pool use was essentially an ecologic design - the unit of analysis was the school. Though the study of correlations between asthma prevalence and indexes of pool use respects this (the $\mathrm{p}$ values are appropriate), the logistic regression analysis does not. The analysis is carried out as if there were 1881 independent observations of asthma and swimming pool use. In fact, observations are not independent-there is "clustering" of asthma by school-even after allowing for effects of swimming pool use and other covariates. The extremely low $\mathrm{p}$ values in fig 6 therefore cannot be relied on. The analysis applied to the study of chronic effects on lung epithelium is also limited in not allowing for possible clustering by school. Again, the $\mathrm{p}$ values presented overestimate the strength of evidence for an association.

Caution is also required in interpreting the correlations and $\mathrm{p}$ values in figs $5 \mathrm{C}$ and $5 \mathrm{D}$. These do not test the association of asthma with pool use, but with a composite index of pool use, pets, and passive smoking. It is not possible from the results presented to distinguish the contribution of each. The authors acknowledge this, but reader confusion may arise because the term "adjusted" is more usually used in epidemiology to describe adjustment for confounding of one effect by another-this is not the case here.

Finally, the correlations shown in figs 5A and $5 \mathrm{~B}$ are selected from a wider range of measures of pool attendance, as shown in fig 4 . Among these non-independent indices of exposure, the authors have chosen the one showing the strongest correlation with asthma prevalence. For this reason, the "significance" of the $\mathrm{p}$ value in fig $5 \mathrm{~B}$ should be interpreted as suggestive rather than definitive.

We conclude that the epidemiological evidence for an association of asthma with swimming pool use is not as strong as claimed by the authors.

B Armstrong

Public and Environmental Health Unit, London Schoo of Hygiene and Tropical Medicine, Keppel St London WCIE 7HT, UK; ben.armstrong@lshtm.ac.uk

D Strachan

Department of Public Health Sciences, St George's Hospital Medical School, Cranmer Terrace, London SW17 ORE, UK doi: 10.1136/oem.2003.011205

\section{Reference}

1 Bernard A, Carbonnelle S, Michel O, et al. Lung hyperpermeability and asthma prevalence in schoolchildren: unexpected associations with the attendance at indoor chlorinated swimming pools. Occup Environ Med 2003;60:385-94. 


\section{Authors' reply}

Although we appreciate the interest of Dr Armstrong and Dr Strachan for our paper on the pool chlorine/asthma risk, we cannot really take on board their reasoning concerning the statistical analyses. When questioning the strength of the associations found in our studies, they seem indeed to attribute much importance to the $p$ values of the associations emerging between cumulated pool attendance and indicators of asthma or lung epithelium permeability. The $\mathrm{p}$ values, however, are not reliable indicators to judge of the strength of associations found in epidemiology since they are highly dependent on the number of observations. Our assessment of the strength of these associations was therefore based more on the values of $r^{2}$ and on the fact that the associations found with pool chlorine exposure were much stronger than those emerging (and a fortiori not emerging) with other variables classically presented as possible contributors to asthma and lung damage in children (for example, environmental tobacco smoke, pets, outdoor pollution)

With regard to the third study linking asthma prevalence and pool attendance, we agree of course that this is a retrospective ecological study carried out by aggregating data from each school, which was made possible due to the fact that pool attendance is a compulsory activity in Belgian primary schools. However, since this study was not specifically designed to assess the effects of pool chlorine, in our opinion, its major weakness lies less in this school based aggregation than in the fact that we could not quantify the cumulated pool chlorine exposure of these children on an individual basis, some of them having certainly attended a chlorinated pool with their parents (recreational, baby swimming, etc) or as part of a sport activity. This is the reason why we cautiously concluded our paper by recommending further studies to test this chlorine hypothesis. We have now just completed such a study exploring the links between asthma, lung inflammation, atopy, and cumulated exposure of children to pool chlorine. The results clearly show that the associations published in $O E M$ were far from having been overestimated (Bernard et al, manuscript in preparation).

A Bernard, $C$ de Burbure Department of Public Health, Catholic University of Louvain, 30.54 Clos Chapelle-aux-Champs, B-1200 Brussels, Belgium; bernard@toxi.ucl.ac.be

\section{BOOK REVIEWS}

\section{Exposure assessment in occupational and environmental epidemiology}

Edited by Mark J Nieuwenhuijsen (pp 283). Oxford University Press, UK, 2003. £36.50. ISBN 0-19-852861-2

While exposure assessment for occupational epidemiology has been developed over many years, the application of exposure assessment, other than of the crudest kind, in environmental epidemiology is relatively new. In the majority of epidemiological investigations, rather basic surrogate measures of exposure are applied with very strong possibilities for misclassification of exposure, and therefore in most instances a weakening of the power of the study. There is, therefore much to gain from application of improved exposure assessment methods. This book provides the necessary foundation. Mark Nieuwenhuijsen's book, in the words of the preface, is aimed at a very wide audience including undergraduate and postgraduate courses in a range of disciplines and as a reference book for policy makers and regulators. The book comprises 17 chapters divided into two sections, the first on methods, the second on current topics. The methods range from questionnaires through dispersion modelling, use of geographic information systems, personal exposure monitoring, modelling of personal exposures, retrospective exposure assessment, exposure surrogates, dermal exposure assessments, physiologically based pharmacokinetic modelling, biological monitoring, and finally an interesting chapter on the consequences of exposure measurement error. In the second section on current topics there are five individual chapters dealing with allergen exposure, airborne particulate matter (environmental exposures), chlorination disinfection by-products, pesticides, and radio frequency exposures in relation to cancer. Dr Nieuwenhuijsen has assembled an impressive international list of contributors and the individual chapters, although relatively short, mostly present a relatively comprehensive overview of the relevant subject area. I looked particularly closely at sections dealing with airborne particulate matter, as this is a personal interest, and found the subject to arise in a number of chapters in the first section of the book, in addition to the current topic chapter. The latter can be complimented on being especially up-to-date, much of it being based on work published between 2000 and 2002. The one topic which, although touched on is not dealt with in an appropriate level of detail, is the technology for measuring personal exposure, particularly the area of environmental exposures. Development of new techniques is at the cutting edge of the subject and this would have been a valuable component of the book. In all other senses I found the book to be a very thorough treatment of the subject, easy to read, and by authoritative authors. It is very up-to-date and accurate; I was only able to find one obvious error. I am not aware of any obviously competitive titles and the book deserves to do well. It is a little on the expensive side for a softback, but nonetheless offers good value for money. I would however question the intended market. I would be surprised to see the book used substantially for undergraduate teaching except perhaps in highly specialised courses. Its readership will lie far more with postgraduate courses and especially with those professionally involved in epidemiology and exposure assessment. For that last group, it will prove a very valuable addition to the private bookshelf and institutional library.

R M Harrison

\section{Epidemiology for the uninitiated, 5th edition}

David Coggon, Geoffrey Rose, David G P Barker (pp 73; £12.95), 2003. London: BM Books. ISBN 0727916041

This well known, short, introductory text has established its place in the literature of epidemiology. The first edition appeared in 1979 and it has been updated regularly. As an introduction it can be warmly recommended.

The authors have set out to explain what epidemiology is and how epidemiological studies should be conducted and interpreted in just 70 pages: a hard task. The chapters are short but cover the field in unexpected detail. Emphasis is placed on why certain study designs are applicable to certain problems and on the strengths and weaknesses of individual approaches. Mathematical details are not included and the innumerate have little to fear. Hard thinking is, however, needed! The emphasis placed on excluding, as far as possible, causes of bias is very necessary. This is stressed for each design considered: even experienced workers might learn something from this. Of course, no book as short as this can explore difficult areas in depth and in places this has led the authors into employing a didactic approach; one can find points for further discussion. Consider, for example, the following statement (page 17):

"Confounding determines the extent to which observed associations are causal $^{\prime \prime}$

Discuss - as the examiners used to say in the days of essay based examinations. Of course, the statement as it stands is incorrect and the authors explain the real effects of confounding clearly.

This is not a cook-book of how to do epidemiological studies but I would have liked to have read a chapter entitled:

"Problems likely to be solved by epidemiological studies and problems unlikely to be solved",

with some examples. The authors might like to consider this for the next edition which will certainly be called for in a few years time.

In summary then, an admirable introduction that should be read by all medical students and, again, by all contemplating undertaking an epidemiological study.

R L Maynard

\section{NOTICE}

\section{IRAS courses and MSc, Utrecht, Netherlands}

The following courses are available:

- Two year MSc course in Toxicology and Environmental Health, starting in February 2005 and September 2005.

- Four day course in Risk Assessment, 7-10 June 2004.

- Five day course in Epidemiology for Toxicologists, 23-27 August 2004.

- Four-day course in Ventilation Design, 20-23 September 2004.

Contact address: education@iras.uu.nl. Website: www.iras.uu.nl. 